\title{
The PRODIGE 7 randomized trial has 4 design flaws and 4 pharmacologic flaws and cannot be used to discredit other HIPEC regimens
}

\author{
Paul H. Sugarbaker ${ }^{1}$, Kurt Van der Speeten ${ }^{2}$ \\ ${ }^{1}$ MedStar Washington Hospital Center, Washington, DC, USA; ${ }^{2}$ Department of Surgery, Hospital Oost-Limburg, Genk, Belgium \\ Correspondence to: Paul H. Sugarbaker, MD. MedStar Washington Hospital Center, Washington, DC, USA. Email: Paul.Sugarbaker@outlook.com; \\ Kurt Van der Speeten. Department of Surgery, Hospital Oost-Limburg, Genk, Belgium. Email: Kurt.Vanderspeeten@zol.be. \\ Comment on: Cashin P, Sugarbaker PH. Hyperthermic intraperitoneal chemotherapy (HIPEC) for colorectal and appendiceal peritoneal metastases: \\ lessons learned from PRODIGE 7. J Gastrointest Oncol 2021;12:S120-8.
}

Submitted Dec 16, 2020. Accepted for publication Mar 16, 2021.

doi: 10.21037/jgo-2020-15

View this article at: http://dx.doi.org/10.21037/jgo-2020-15

The contributions to our Focused Issue regarding colorectal and appendiceal cancer are, by design, limited. The initial contribution regarding "Lessons learned from PRODIGE 7" should reassure peritoneal surface oncology physicians, nurses, and paramedical personnel that HIPEC is not dead as a result of this RCT (1). First, the unprecedented 41 months OS in both the experimental arm (CRS + HIPEC) and standard arm (CRS) clearly demonstrate CRS by itself as a standard of care for resectable colorectal PM. Sixteen patients (12\%) of the CRS only group crossed over to receive CRS plus HIPEC. This becomes a statistical nightmare for which no solution currently exists. In contrast, the relapse-free survival is statistically significantly positive (Fisher exact $\mathrm{p}=0.049$ ). The effects of neoadjuvant FOLFOX on HIPEC with oxaliplatin have never been defined. We comment about 4 design flaws and 4 pharmacologic flaws in protocol strategy and implementation that must raise doubts concerning conclusions drawn from this RCT. Next to that, one of the main lessons learned from PRODIGE 7 analysis is not that oxaliplatin is a bad drug for IP use but that it was rather badly used in the current dosimetry and duration (2).

\section{Acknowledgments}

Funding: None.

\section{Footnote}

Provenance and Peer Review: This article was commissioned by the editorial office, Fournal of Gastrointestinal Oncology for the focused issue "Intraperitoneal Chemotherapy for Peritoneal Metastases: HIPEC, EPIC, NIPEC, PIPAC and More". The article did not undergo external peer review.

Conflicts of Interest: Both authors have completed the ICMJE uniform disclosure form (available at http:// dx.doi.org/10.21037/jgo-2020-15). The focused issue was sponsored by the Peritoneal Surface Oncology Group International (PSOGI). Drs. PHS and KVDS served as the unpaid Guest Editors of the focused issue. The authors have no other conflicts of interest to declare.

Ethical Statement: The authors are accountable for all aspects of the work in ensuring that questions related to the accuracy or integrity of any part of the work are appropriately investigated and resolved.

Open Access Statement: This is an Open Access article distributed in accordance with the Creative Commons Attribution-NonCommercial-NoDerivs 4.0 International License (CC BY-NC-ND 4.0), which permits the noncommercial replication and distribution of the article with 
the strict proviso that no changes or edits are made and the original work is properly cited (including links to both the formal publication through the relevant DOI and the license). See: https://creativecommons.org/licenses/by-nc-nd/4.0/.

\section{References}

1. Cashin P, Sugarbaker PH. Hyperthermic intraperitoneal

Cite this article as: Sugarbaker PH, Van der Speeten K. The PRODIGE 7 randomized trial has 4 design flaws and 4 pharmacologic flaws and cannot be used to discredit other HIPEC regimens. J Gastrointest Oncol 2021;12(Suppl 1): S129-S130. doi: 10.21037/jgo-2020-15 chemotherapy (HIPEC) for colorectal and appendiceal peritoneal metastases: lessons learned from PRODIGE 7. J Gastrointest Oncol 2021;12:S120-8.

2. Quenet F, Elias D, Roca L, et al. A UNICANCER phase III trial of hyperthermic intraperitoneal chemotherapy (HIPEC) for colorectal peritoneal carcinomatosis: PRODIGE 7. J Clin Oncol 2018;36:LBA3503. 